\title{
Awareness and Knowledge of Saudi Community about Cardiac Complications Resulting from Hyperthyroidism
}

\author{
Khalid Alghamdi ${ }^{1}$, Rinad Almaliki ${ }^{* 2}$, Khaled Almaliki ${ }^{2}$, Waad Alzahrani ${ }^{2}$, Rana Malyani ${ }^{2}$, \\ Yomna Samaran ${ }^{2}$, Khames Alzahrani ${ }^{3}$ \\ ${ }^{1}$ Specialized Polyclinic, Ministry of Interior Security Forces Medical Services, Jeddah, Kingdom of Saudi Arabia \\ ${ }^{2}$ Medical Student, College of Medicine, Taif University, Taif, Saudi Arabia \\ ${ }^{3}$ BDS, PGD Endo, Ministry of Health, Taif, Saudi Arabia
}

*Corresponding author: Renad Almaliki; Dr.rinadsa@gmail.com

Received 15 June 2021;

Accepted 07 July 2021;

Published 20 July 2021

\subsection{Abstract}

Background: The misconceptions about thyroid disorders and the associated complications in many counties are a considerable concern. Thyroid disorders are amongst worldwide common endocrine disorders. Based on the World Health Organization, more than 190 million individuals have iodine deficiency disorders. Most importantly, hyperthyroidism alters the cardiovascular (CV) hemodynamic. Methods: A cross-sectional observational survey study that was carried out in Saudi Arabia using an online self-prepared questionnaire including sociodemographic data, disease manifestations, diagnosis, family history, and question regarding hyperthyroidism and CV complications. That was distributed, via a link to Google form, to the general public. Only completed surveys were included in the analysis. Data were represented in the form of frequencies (number of responders) and valid percentages for categorical variables. ANOVA test was utilized to compare means between different subgroups. All P values $<0.05$ were considered statistically significant. Result: A total of 641 participants took part in this study and achieved a mean score of 4.7 (SD 1.5) of the total score obtainable regarding hyperthyroidism. Out of them, 51.3\% did not perform thyroid hormones investigation or having family history of thyroid disorders $(46.8 \%)$. Adequate knowledge was seen regarding the occurring of heart diseases as a complication of hyperthyroidism (80.5\%) and preventing CV disease by treating hyperthyroidism (88.6\%). $68.8 \%$ did not know which heart complications result from hyperthyroidism. There was a statistically significant relationship between the level of knowledge and age $(\mathrm{p}<0.001)$, sex $(\mathrm{p}=0.004)$, undergoing previous thyroid investigations $(\mathrm{p}=0.003)$ and being diagnosed with previous thyroid disease $(\mathrm{p}<0.001)$. Nationality and education had no significant effect on the knowledge level of the participants. Conclusion: In this study, the overall level of Knowledge about thyroid disorders in the community was limited. Better knowledge was found about CV complications of hyperthyroidism. Educational programs will have a positive influence of awareness on thyroid troubles and will help in early diagnosis of these disorders and prevent $\mathrm{CV}$ diseases.

Keywords: Hyperthyroidism, Thyroid Disorders, Cardiac Complications.

\section{Introduction}

\subsection{Definition and epidemiology}

Thyroid disorders are amongst worldwide common endocrine disorders. Based on the World Health Organization, more than 190 million individuals have iodine deficiency disorders ${ }^{[1]}$.

Hyperthyroidism prevalence is approximately $1.3 \%$ and it varies by age, sex, race/ethnicity, and geographically through variations in dietary iodine intake ${ }^{[2,3]}$. Hyperthyroidism is 5 times more common in females than males and increases in older women ${ }^{[4]}$. In younger women, Graves' disease is seen more frequently, whereas in older women, toxic nodular goiter is seen more. Similarly, hyperthyroidism is more common in smokers ${ }^{[5]}$.

\subsection{Manifestations of hyperthyroidism:}

Most of the hyperthyroidism symptoms are not specific and can be easily confused with other medical conditions. The classic hyperthyroidism symptoms are including tremor, sweating, anxiety, weight loss, menstrual issues, increased bowel movements frequency, fatigue, and shortness of breath ${ }^{[6,7]}$. The clinical sign and symptoms of hyperthyroidism are mainly not related to the high serum thyroid hormone concentrations. 
Most importantly, hyperthyroidism alters the cardiovascular (CV) hemodynamics. CV manifestations are common in patients with hyperthyroidism ${ }^{[8]}$. Thyroid hormone has effects on myocardium, the peripheral circulation, and sympathetic nervous system ${ }^{[9]}$. Also, hyperthyroidism is associated with multiple CV disease such as atrial fibrillation, heart failure, pulmonary hypertension, and angina ${ }^{[10]}$. CV signs and symptoms can be corrected by treating hyperthyroidism. Congestive heart failure can be avoided by an early and effective management of hyperthyroidism $^{[10]}$.

\subsection{Diagnosis and detection}

Thyroid disorders are frequently under-diagnosed. There are several factors affecting early diagnosis and detection of hyperthyroidism. One of these factors is the poor knowledge and lack of awareness about these diseases which can lead patients to go undiagnosed [11]. Furthermore, there is limited data on the knowledge and awareness among cardiac complications resulting from hyperthyroidism patients ${ }^{[12]}$.

In light of the above, the present study aimed to determine the degree of knowledge of hyperthyroidism and the associated CV disorders among the Saudi population to develop awareness and educational measures for assisting in the early diagnosis of such disorders and prevent $\mathrm{CV}$ complications.

\section{Subjects and Methods}

\subsection{Study design}

This cross-sectional study is a questionnaire-based assessment of general population in Saudi Arabia distributed during 2020, to evaluate and their level of knowledge and their awareness of CV complications of hyperthyroidism. All individuals who agreed to participate from all age groups and both sexes were included in the study.

\subsection{Data collected}

A self-prepared questionnaire was developed. The questionnaire was divided into four parts:

Table 1: Demographic data of participants

\begin{tabular}{|c|c|c|c|}
\hline \multicolumn{2}{|l|}{ Demographic data } & \multirow{2}{*}{$\begin{array}{l}\text { Count } \\
\mathbf{N}=\mathbf{6 4 1} \\
13\end{array}$} & \multirow{2}{*}{$\begin{array}{l}\text { Percentage } \\
2.0\end{array}$} \\
\hline \multirow{7}{*}{ Age group } & Less than 15 years & & \\
\hline & 15 to 19 & 26 & 4.1 \\
\hline & 20 to 29 & 225 & 35.1 \\
\hline & 30 to 39 & 84 & 13.1 \\
\hline & 40 to 49 & 188 & 29.3 \\
\hline & 50 to 59 & 97 & 15.1 \\
\hline & 60 years or more & 8 & 1.2 \\
\hline \multirow{2}{*}{ Gender } & Male & 140 & 21.8 \\
\hline & Female & 501 & 78.2 \\
\hline \multirow{2}{*}{ Nationality } & Saudi & 618 & 96.4 \\
\hline & Non-Saudi & 23 & 3.6 \\
\hline \multirow{5}{*}{ Educational level } & Primary & 1 & 0.2 \\
\hline & Intermediate & 28 & 4.4 \\
\hline & Secondary & 130 & 20.3 \\
\hline & Bachelor & 439 & 68.5 \\
\hline & High education & 43 & 6.7 \\
\hline \multirow{4}{*}{ Residency } & Jeddah & 345 & 53.8 \\
\hline & Makkah & 145 & 22.6 \\
\hline & Altaif & 141 & 22.0 \\
\hline & Others & 10 & 1.6 \\
\hline
\end{tabular}

1. Demographic characteristics including age, gender, nationality, residency, and educational level.

2. Questions regarding family history and previous diagnosis of thyroid diseases.

3. Questions regarding knowledge of hyperthyroidism, discontinuation of hyperthyroidism drugs and the extent of the relationship of hyperthyroidism to heart diseases.

\subsection{Sample size}

The sample size was estimated using the Raosoft calculator with a confidence level of $95 \%$; a sample size of 641 .

\subsection{Statistical methodology}

Data were statistically described in terms of frequencies (number of cases) and valid percentages for categorical variables. Comparison of two means between the groups was done using One-way analysis of variance (ANOVA). P values less than 0.05 were considered statistically significant. All statistical calculations were done using computer program IBM SPSS (Statistical Package for the Social Science; IBM Corp, Armonk, NY, USA) release 21 for Microsoft Windows.

\subsection{Ethical considerations:}

During the research activities, each studied participant was informed about the study topic and objectives with stressing from our team on confidentiality of the collected data and sample results, and also on getting a written consent to share in the study.

\section{Results}

\subsection{Demographic data:}

A total of 641 individuals were contributed in the study. Approximately one third of the response aged from 20 to 29 $(35.1 \%)$ then from 40 to $49(29.3 \%)$. Out of them, $501(78.2 \%)$ were female. Ninety-six percent of the participants were Saudi. The majority of participants had Bachelor degree (68.5\%). Majority of participants were from Jeddah (53.8\%). Demographics, education, nationality and residency characteristics of the participants are presented in table 1. 


\subsection{Thyroid investigations}

Participants were asked about their thyroid hormone investigations. Fifty-one percent of them did not perform thyroid hormones investigation. From those who performed thyroid analysis, the highest motive to perform analysis was to ensure general health
(21.4\%). Only $8.3 \%$ of participants were diagnosed by a doctor of hyperthyroidism. Out of those who were diagnosed with thyroid troubles, the highest percentage was diagnosed at age from 20 to 29 years old $(2.4 \%)$. More details are shown in table 2.

Table 2: Thyroid diagnosis among participants

\begin{tabular}{|c|c|c|c|}
\hline \multicolumn{2}{|l|}{ Thyroid diagnosis } & \multirow{2}{*}{$\begin{array}{l}\text { Count } \\
\mathbf{N}=\mathbf{6 4 1} \\
312\end{array}$} & \multirow{2}{*}{$\begin{array}{l}\text { Percent } \\
48.7\end{array}$} \\
\hline Have you ever performed tests to & Yes & & \\
\hline measure the level of thyroid hormones? & No & 329 & 51.3 \\
\hline \multirow{6}{*}{$\begin{array}{l}\text { What motivated you to perform these } \\
\text { tests? }\end{array}$} & I did not perform any thyroid tests & 293 & 45.7 \\
\hline & comprehensive tests that I did to ensure your health & 137 & 21.4 \\
\hline & I made it at a special request from your doctor & 92 & 14.4 \\
\hline & the appearance of thyroid symptoms & 73 & 11.4 \\
\hline & It was suggested to you by one of your relatives / friends. & 13 & 2.0 \\
\hline & Other & 33 & 5.1 \\
\hline \multirow{2}{*}{$\begin{array}{l}\text { Have you been diagnosed by a doctor } \\
\text { with hyperthyroidism? }\end{array}$} & Yes & 53 & 8.3 \\
\hline & No & 588 & 91.7 \\
\hline \multirow{6}{*}{$\begin{array}{l}\text { When was the first time you were } \\
\text { diagnosed with hyperthyroidism? }\end{array}$} & I have not been diagnosed & 557 & 86.9 \\
\hline & 15 to 19 & 18 & 2.8 \\
\hline & 20 to 29 & 27 & 4.2 \\
\hline & 30 to 39 & 17 & 2.7 \\
\hline & 40 to 49 & 17 & 2.7 \\
\hline & 50 to 59 & 5 & 0.8 \\
\hline
\end{tabular}

\subsection{Family history of thyroid disorders}

Among participants, $46.8 \%$ did not have family history of thyroid disorders, while family history of hypothyroidism was reported in
$32.6 \%$. Hyperthyroidism family history was reported in $14.5 \%$ and $5.6 \%$ had both hypo and hyperthyroidism diseases (figure 1)

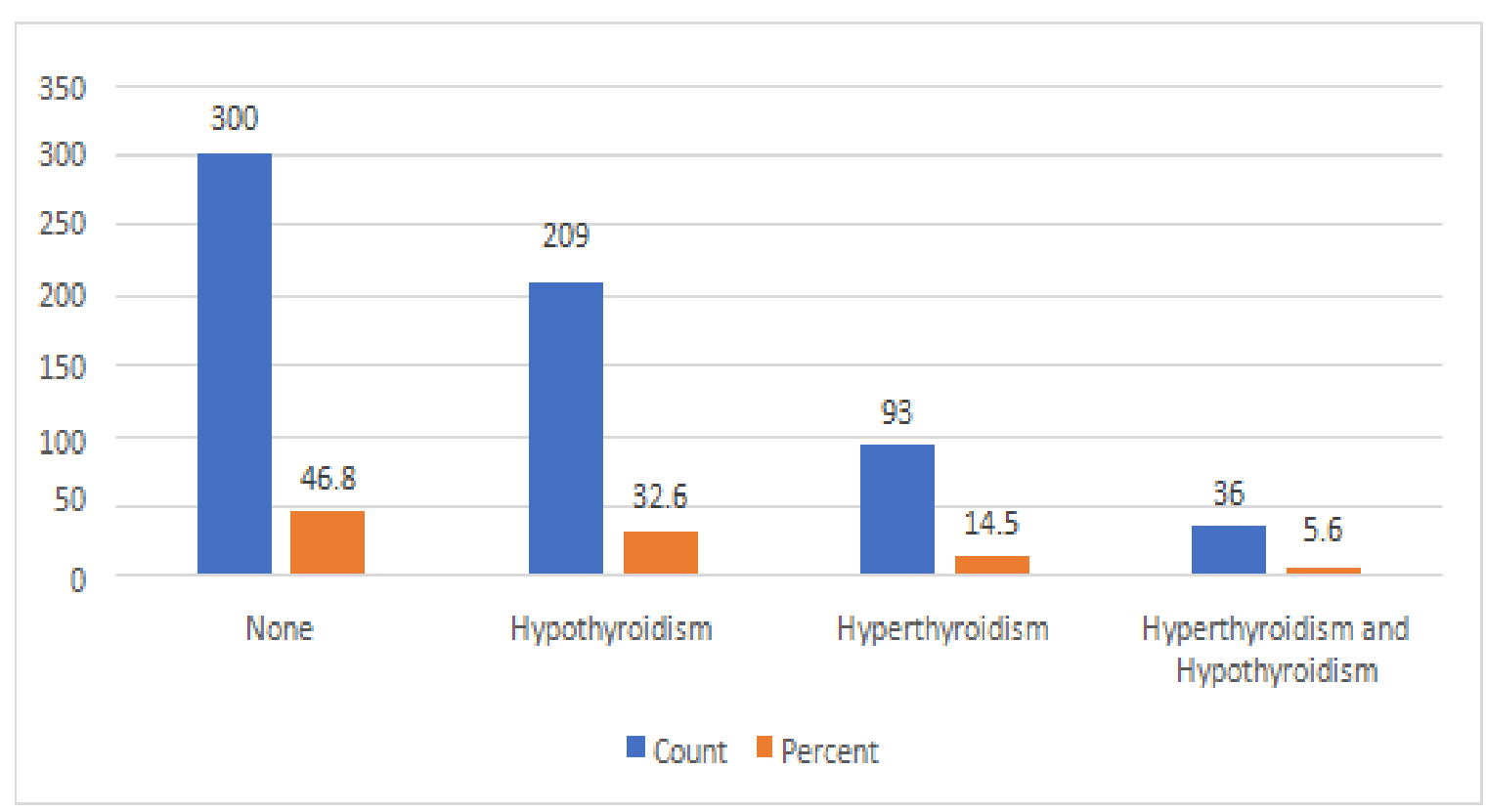

Figure 1: Family history of thyroid disorders among participants

\subsection{Assessing Knowledge about hyperthyroidism}

Based on the results regarding the general knowledge regarding thyroid disease, respondents showed adequate knowledge for overactive thyroid gland definition $(74.6 \%)$, unintentional weight loss as a symptom of hyperthyroidism $(67.4 \%)$, not stopping using hyperthyroidism medication without consulting a doctor $(76.1 \%)$ as well as not stopping it in pregnancy (76.4\%). Moderate knowledge was found regarding hyperthyroidism is being genetically transmitted $(55.2 \%)$. A poor knowledge was reported regarding symptoms of hyperthyroidism. Concerning respondents' knowledge about cardiac complications; respondents showed sufficient knowledge regarding the occurring of heart diseases as a complication of hyperthyroidism (80.5\%); however, $68.8 \%$ did not know which heart complications could result from hyperthyroidism. The majority of participants believed that treating hyperthyroidism could prevent CV disease (88.6\%).

Moreover, the overall mean knowledge score regarding thyroid disorders was 4.7 (SD 1.5).

Table 3 presents the descriptive statistics of the knowledge regarding thyroid disease. 
Table 3: Participants' Knowledge about hyperthyroidism

\begin{tabular}{|c|c|c|c|c|}
\hline \multicolumn{3}{|c|}{ 4.5. Knowledge about hyperthyroidism } & $\begin{array}{l}\text { Count } \\
\mathrm{N}=641\end{array}$ & Percent \\
\hline \multirow{3}{*}{1} & \multirow{3}{*}{ What does an overactive thyroid gland mean? } & $\begin{array}{l}\text { A condition in which the thyroid gland produces a } \\
\text { large amount of the hormone thyroxine }\end{array}$ & 478 & 74.6 \\
\hline & & $\begin{array}{l}\text { A condition in which the thyroid gland produces a } \\
\text { large amount of the hormone cortisol }\end{array}$ & 109 & 17.0 \\
\hline & & $\begin{array}{l}\text { A condition in which the thyroid gland produces a } \\
\text { large amount of the hormone melatonin }\end{array}$ & 54 & 8.4 \\
\hline \multirow[b]{2}{*}{2} & \multirow{2}{*}{$\begin{array}{l}\text { Do you think hyperthyroidism can be transmitted } \\
\text { genetically? }\end{array}$} & Yes & 354 & 55.2 \\
\hline & & No & 287 & 44.8 \\
\hline \multirow{10}{*}{3} & \multirow{10}{*}{ What are the symptoms of hyperthyroidism? } & $\begin{array}{l}\text { Unintentional weight loss even when there is an } \\
\text { increased appetite }\end{array}$ & 432 & 67.4 \\
\hline & & Rapid heartbeat & 253 & 39.5 \\
\hline & & Fine, brittle hair & 253 & 39.5 \\
\hline & & Increased sweating & 228 & 35.6 \\
\hline & & weight gain and face swelling & 205 & 32.0 \\
\hline & & Tremor & 203 & 31.7 \\
\hline & & Irregular heartbeat & 161 & 25.1 \\
\hline & & Excessive sensitivity to heat & 160 & 25.0 \\
\hline & & Muscles weakness & 142 & 22.2 \\
\hline & & Dry skin & 133 & 20.7 \\
\hline \multirow[t]{2}{*}{4} & \multirow{2}{*}{$\begin{array}{l}\text { Can you stop using hyperthyroidism medication without } \\
\text { consulting a doctor if your tests are normal? (If you are } \\
\text { not affected, would you advise a hyperthyroid patient to } \\
\text { stop using the drugs if his tests are normal? }\end{array}$} & Yes & 153 & 23.9 \\
\hline & & No & 488 & 76.1 \\
\hline \multirow[t]{2}{*}{5} & \multirow[b]{2}{*}{$\begin{array}{l}\text { Can you stop using hyperthyroidism medication during } \\
\text { pregnancy without consulting a doctor because you think } \\
\text { they cause congenital defects? (If you are not affected, } \\
\text { would you advise a hyperthyroid patient to stop using the } \\
\text { drugs if his tests are normal? }\end{array}$} & Yes & 151 & 23.6 \\
\hline & & No & 490 & 76.4 \\
\hline \multirow[t]{2}{*}{6} & \multirow{2}{*}{$\begin{array}{l}\text { Do you think that heart disease may occur as a result of } \\
\text { hyperthyroidism? }\end{array}$} & Yes & 516 & 80.5 \\
\hline & & No & 125 & 19.5 \\
\hline \multirow[t]{3}{*}{7} & \multirow{3}{*}{$\begin{array}{l}\text { What are the heart complications resulting from } \\
\text { hyperthyroidism? }\end{array}$} & Myocarditis / Pericarditis & 71 & 11.1 \\
\hline & & Atrial Fibrillation / Congestive Heart Failure & 129 & 20.1 \\
\hline & & I Don't Know & 441 & 68.8 \\
\hline \multirow[t]{2}{*}{8} & \multirow{2}{*}{$\begin{array}{l}\text { Do you think that treating hyperthyroidism can prevent } \\
\text { cardiovascular disease? }\end{array}$} & Yes & 568 & 88.6 \\
\hline & & No & 73 & 11.4 \\
\hline \multicolumn{2}{|r|}{ Total score $($ Mean $\pm(\mathrm{SD})$} & Min-Max & & $(0-7)$ \\
\hline
\end{tabular}

\subsection{Overall Knowledge of hyperthyroidism}

In Table 4, the differences in the level of knowledge in relation to the demographic characteristics of the respondents as well as the previous history of thyroid diseases were discussed in details. It was found that the knowledge of the participants was statistically significant with variables such as; gender $(\mathrm{p}=0.004)$, age $(\mathrm{p}<0.001)$, undergoing previous thyroid investigations $(\mathrm{p}<0.003)$, and being diagnosed with thyroid disease $(p<0.001)$. Meanwhile nationality and educational level did not show a significant difference when compared to the overall knowledge score (all $\mathrm{p}>0.05$ ).

Table 4: Statistical differences between the mean knowledge score and demographic characteristics and diagnosis of hyperthyroidism among participants

\begin{tabular}{|c|c|c|c|c|c|c|}
\hline & & Mean & SD & Minimum & Maximum & P-value \\
\hline \multirow{2}{*}{ Nationality } & Saudi & 47 & 1.5 & 0.00 & 7.00 & \multirow[t]{2}{*}{0.510} \\
\hline & Non-Saudi & 4.9 & 1.3 & 2.00 & 7.00 & \\
\hline \multirow{2}{*}{ Gender } & Male & 5.0 & 1.5 & 1.00 & 7.00 & \multirow[t]{2}{*}{$0.004 *$} \\
\hline & Female & 4.6 & 1.4 & 0.00 & 7.00 & \\
\hline \multirow{7}{*}{ Age group } & $<15$ years & 4.7 & 1.3 & 2.00 & 6.00 & \multirow{7}{*}{$<0.001 *$} \\
\hline & 15 to 19 & 5.1 & 1.1 & 2.00 & 7.00 & \\
\hline & 20 to 29 & 5.2 & 1.4 & 1.00 & 7.00 & \\
\hline & 30 to 39 & 4.5 & 1.3 & 2.00 & 7.00 & \\
\hline & 40 to 49 & 4.4 & 1.5 & 0.00 & 7.00 & \\
\hline & 50 to 59 & 4.2 & 1.4 & 0.00 & 6.00 & \\
\hline & $\geq 60$ years & 3.9 & 1.4 & 2.00 & 6.00 & \\
\hline
\end{tabular}




\begin{tabular}{|c|c|c|c|c|c|c|}
\hline \multirow{5}{*}{ Educational level } & Primary & 6.0 & 0.5 & 6.00 & 6.00 & \multirow{5}{*}{0.387} \\
\hline & Intermediate & 4.3 & 0.9 & 2.00 & 6.00 & \\
\hline & Secondary & 4.8 & 1.3 & 1.00 & 7.00 & \\
\hline & Bachelor & 4.7 & 1.5 & 0.00 & 7.00 & \\
\hline & High education & 4.7 & 1.3 & 2.00 & 7.00 & \\
\hline \multirow{2}{*}{$\begin{array}{l}\text { Previous lab } \\
\text { investigation }\end{array}$} & Yes & 4.9 & 1.4 & 1.00 & 7.00 & \multirow[b]{2}{*}{$0.003^{*}$} \\
\hline & No & 4.6 & 1.5 & 0.00 & 7.00 & \\
\hline \multirow{2}{*}{$\begin{array}{l}\text { Diagnosis of } \\
\text { hyperthyroidism }\end{array}$} & Yes & 4.1 & 1.5 & 0.00 & 7.00 & \multirow[t]{2}{*}{$<0.001 *$} \\
\hline & No & 4.7 & 1.4 & 0.00 & 7.00 & \\
\hline
\end{tabular}

(*) $P<0.05=$ Statistically significant

\section{Discussion}

Thyroid disorders are amongst the most underdiagnosed health problems, and the lack of community knowledge about the disease is considered an issue ${ }^{[11]}$. Awareness can benefit many individuals who have thyroid disease and are unaware of their problem ${ }^{[13]}$.

Very little is known about the level of knowledge about hyperthyroidism and its complications on CV system ${ }^{[12]}$. Most of the studies were conducted on the knowledge of the all thyroid diseases (hypo and hyperthyroidism) or on hypothyroidism alone, the risk factors and the diagnosis ${ }^{[11,12,14]}$.

In this cross-sectional study, it was designed to determine the degree of knowledge of hyperthyroidism and its CV complications, the diagnosis and past medical history among the Saudi community to develop awareness programs for tackling the problem of early detection of hyperthyroidism disorders.

In the current study, we provide information on patterns of community-based level of awareness among Saudi population regarding thyroid disorders. The total number of participants was 641 among which $78.2 \%$ were females. The respondents were classified into 7 age groups; most of them were in the 20 to 29 (35.1\%) years old group. $68.5 \%$ of the respondents had Bachelor degree.

In the present study, less than half of participants (48.7\%) performed thyroid investigations. The highest motive to perform analysis was to ensure general health $(21.4 \%)$ then doctor's recommendation $(8.3 \%)$. In prior studies ${ }^{[11,14,15]}$, most of the respondents did not undergo thyroid gland investigations (25.2 \& $37.9 \& 47.1 \%)$ and the highest reason also was for routine check $(39.2 \%)^{[14]}$ or doctor's suggestions $(20.1 \% \& 73.02)^{[11,15]}$.

In the present study, we also analyzed the family history of thyroid disorders. Nearly half of participants did not have family history of thyroid disorders $(46.8 \%)$, while family history of hyperthyroidism were the lowest reported thyroid disorders than hypothyroidism. Similarly to our results, in other studies conducted, Saudi Arabia; 52.1 to 59.3\% of individuals did not have a family history of thyroid diseases ${ }^{[14,15]}$. Hyperthyroidism was the least disease detected (12.5\%). In another study conducted at India, only $18 \%$ of respondents had a family history of thyroid disorders (hyper or hypothyroidism) ${ }^{[11]}$.

As seen in our study, our participants have a limited level of the overall knowledge regarding thyroid disorders where the overall mean knowledge score was 4.7 (SD 1.5). Poor knowledge of thyroid troubles is a concern in Saudi Arabia and in many countries ${ }^{[11,12,14,15]}$. Unlike women in Selangor, most of them have good knowledge and awareness ${ }^{[16]}$.

The findings of the study further indicated adequate general knowledge regarding what is hyperthyroidism (74.6\%), and unintentional weight loss as a symptom of hyperthyroidism $(67.4 \%)$. Our results were in accordance with another study conducted among Saudi people ${ }^{[12]}$. Loss of weight despite good appetite is a symptom of hyperthyroidism (79.7\%). In contrary to our results concerning high awareness about not stopping using hyperthyroidism medication without consulting a doctor $(76.1 \%)$ and stopping them in pregnancy (76.4\%), $27 \%$ of respondents among the Riyadh population thought that stopping treatment of hyperthyroidism when the investigations were normal and in pregnancy due to harm of the fetus ${ }^{[15]}$.

Knowledge of cardiac complications resulting from hyperthyroidism is an important aspect. Most of conducted studies that assessed the community knowledge of thyroid diseases, did not evaluate the $\mathrm{CV}$ complications. As seen in our study, a better knowledge of the CV complications was reported. The current study showed $80.5 \%$ agreed on the occurring of heart diseases as a complication of hyperthyroidism; nevertheless, $68.8 \%$ of them did not know which cardiac complications could result from hyperthyroidism. The number of participants increased (88.6\%) who believed that treating hyperthyroidism could prevent $\mathrm{CV}$ disease. Our results were better than another study conducted among Saudi people ${ }^{[12]}$. Only $59 \%$ believed that thyroid dysfunction results in cardiac diseases.

In our study, moderate knowledge was found regarding hyperthyroidism is being genetically transmitted (55.2\%). Different reported knowledge was found among Saudi population. In one study, $42.1 \%$ thought it is genetic ${ }^{[12]}$ and among Riyadh population, only $19.3 \%$ though thyroid dysfunction can be genetically transmitted ${ }^{[15]}$. At the same time, a general poor knowledge in the present study was found regarding symptoms of hyperthyroidism.

Study results further exhibited that there was an association between some of socio- demographic characteristics and level of knowledge and awareness of hyperthyroidism such as gender, age group and undergoing previous thyroid investigations and being diagnosed with thyroid disease.

Our results were in consistent with Alyahya, A., et al., study in 2021 conducted in Eastern Province, Saudi Arabia ${ }^{[14]}$. They reported that having a previous history of thyroid disease, those undergoing thyroid tests and being female had a significant value on better knowledge of thyroid disease. Additionally, in accordance to our results, Canaris et al. study conducted in Michigan, showed an association higher level between that a higher level of knowledge about the thyroid troubles and the prevalence of these disorders ${ }^{[13]}$. On the other hand, Almuzaini et al showed that age and gender had no significant effect on the knowledge level of thyroid troubles ${ }^{[12]}$.

Furthermore, the current study shows that there is no significant difference between educational level and overall knowledge score. Similarly, Almuzaini et al revealed that education was not significantly associated with the level of knowledge of the participants ${ }^{[12]}$.

\section{Conclusion}


Our results show a limited knowledge and awareness among Saudi population regarding hyperthyroidism which may delay the diagnosis. However, more knowledge was seen regarding $\mathrm{CV}$ complications resulting from hyperthyroidism. Educational programs and on thyroid disorders and CV complications for the general population is needed.

\section{Ethics approval}

Institutional research ethics board approval was acquired before conducting any study-related procedures. A statement was included at the beginning of the questionnaire clarifying that the participation in this study is voluntary and that collected data will be anonymous and will only be used for this study.

\section{Conflicts of Interest}

The authors have no conflicts of interest to declare.

\section{Source of Funding}

This study did not receive any specific grant from funding agencies in the public, commercial, or not-for-profit sectors.

\section{References}

[1] World Health Organization, Assessment of iodine deficiency disorders and monitoring their elimination: a guide for programme managers"; 2007

[2] Diab, N., et al., Prevalence and Risk Factors of Thyroid Dysfunction in Older Adults in the Community. Sci Rep, 2019. 9(1): p. 13156.

[3] Meisinger, C., et al., Geographic variations in the frequency of thyroid disorders and thyroid peroxidase antibodies in persons without former thyroid disease within Germany. Eur J Endocrinol, 2012. 167(3): p. 36371.

[4] Hollowell, J.G., et al., Serum TSH, T(4), and thyroid antibodies in the United States population (1988 to 1994): National Health and Nutrition Examination Survey (NHANES III). J Clin Endocrinol Metab, 2002. 87(2): p. 489-99.
[5] Asvold, B.O., et al., Tobacco smoking and thyroid function: a population- based study. Arch Intern Med, 2007. 167(13): p. 1428-32.

[6] Nordyke, R.A., F.I. Gilbert, Jr., and A.S. Harada, Graves' disease. Influence of age on clinical findings. Arch Intern Med, 1988. 148(3): p. 626-31.

[7] Trzepacz, P.T., et al., Graves' disease: an analysis of thyroid hormone levels and hyperthyroid signs and symptoms. Am J Med, 1989. 87(5): p. 558-61.

[8] Osman, F., et al., Cardiovascular manifestations of hyperthyroidism before and after antithyroid therapy: a matched case-control study. J Am Coll Cardiol, 2007. 49(1): p. 71-81.

[9] Klein, I. and K. Ojamaa, Thyroid hormone and the cardiovascular system. N Engl J Med, 2001. 344(7): p. 501-9.

[10] Osuna, P.M., M. Udovcic, and M.D. Sharma, Hyperthyroidism and the Heart. Methodist Debakey Cardiovasc J, 2017. 13(2): p. 60-63.

[11] Rai S, S.S., Khatri AK, Dixit S, Saroshe S., Assessment of knowledge and awareness regarding thyroid disorders among women of a cosmopolitan city of central India. Natl J Community Med., 2016. 7: p. 219-22.

[12] Almuzaini, A., et al., Assessment of knowledge and awareness regarding thyroid disorders among Saudi people. IJMDC, 2019. 3(12): p. 1070- 1076.

[13] Canaris, G.J., T.G. Tape, and R.S. Wigton, Thyroid disease awareness is associated with high rates of identifying subjects with previously undiagnosed thyroid dysfunction. BMC Public Health, 2013. 13(1): p. 351.

[14] Alyahya, A., et al., Knowledge of Thyroid Disease Manifestations and Risk Factors among Residents of the Eastern Province, Saudi Arabia. Cureus, 2021.

[15] Alotaibi, A.M.D. and A.I.S. Almousa, Survey of Awareness of Thyroid Disorders among the Riyadh Population, Central Region of Saudi Arabia. The Egyptian Journal of Hospital Medicine, 2018. 72(2): p. 4039-4044.

[16] Mustafa, M., et al., Knowledge and Awareness of Thyroid Disorder among Women in Selangor 2019. Journal of Pharmaceutical and BioSciences, 2020. 8: p. 7-11. 